\title{
GDNF Signaling Levels Control Migration and Neuronal Differentiation of Enteric Ganglion Precursors
}

\author{
Toshihiro Uesaka, ${ }^{1,3}$ Mayumi Nagashimada, ${ }^{1,2}$ and Hideki Enomoto ${ }^{1,2,3}$ \\ ${ }^{1}$ Laboratory for Neuronal Differentiation and Regeneration, RIKEN Center for Developmental Biology, Kobe 650-0047, Japan, ${ }^{2}$ Department of Development \\ and Regeneration, Graduate School of Medicine, Osaka University, Osaka 565-0871, Japan, and ${ }^{3}$ Division of Neural Differentiation and Regeneration, \\ Department of Physiology and Cell Biology, Graduate School of Medicine, Kobe University, Kobe 650-0017, Japan
}

Pleiotropic growth factors play a number of critical roles in continuous processes of embryonic development; however, the mechanisms by which a single regulatory factor is able to orchestrate diverse developmental events remain imperfectly understood. In the development of the enteric nervous system (ENS), myenteric ganglia (MGs) form initially, after which the submucosal ganglia (SMGs) develop by radial inward migration of immature ENS precursors from the myenteric layer. Here, we demonstrate that glial cell line-derived neurotrophic factor (GDNF) is essential for the formation not only of the MGs, but the SMGs as well, establishing GDNF as a long-term acting neurotrophic factor for ENS development in a mouse model. GDNF promotes radial migration of SMG precursors. Interestingly, premigratory SMG precursors in the myenteric layer were distinguished from the surrounding neuronally differentiating cells by their lower activation of the GDNF-mediated MAPK pathway, suggesting that low activation of GDNF downstream pathways is required for the maintenance of the immature state. ENS precursors devoid of GDNF signaling during midgestation halt their migration, survive, and remain in an undifferentiated state over the long-term in vivo. Reactivation of GDNF signaling in these dormant precursors restores their migration and neuronal differentiation in gut organ culture. These findings suggest that pleiotropic function of GDNF is at least in part governed by modulating levels of intracellular activation of GDNF downstream pathways; high activation triggers neuronal differentiation, whereas low activation is crucial for the maintenance of progenitor state.

\section{Introduction}

Embryonic development is a highly complex, dynamic process that requires exquisite orchestration of cellular proliferation, migration, differentiation, and maintenance of progenitor cells. Cells are exposed to a number of growth factors during development, some of which are expressed for long periods, inducing various cellular responses in tissue progenitors and their progeny. Because impaired regulation of progenitors causes many developmental disorders, it is crucial to understand how a single growth factor governs the behavior of progenitors, including migration, proliferation, and differentiation, and regulates the maintenance of in-tissue progenitors in an undifferentiated state.

The enteric nervous system (ENS) serves as an interesting model for the study of long-term developmental processes in

Received May 16, 2013; revised Sept. 4, 2013; accepted Sept. 6, 2013.

Author contributions: T.U. and H.E. designed research; T.U. and M.N. performed research; T.U. analyzed data; T.U. and H.E. wrote the paper.

This work was supported by RIKEN and Ministry of Education, Culture, Sports, Science and Technology of Japan (Grant-in-Aid for Scientific Research on Innovative Areas, "Cellular and Molecular Basis for Neuro-Vascular Wiring"). We thank the Laboratory for Animal Resources and Genetic Engineering for their excellent technical assistance. We also are grateful to D. Sipp and H.S. Hiraga for editing this manuscript.

The authors declare no competing financial interests.

Correspondence should be addressed to Hideki Enomoto, Division of Neural Differentiation and Regeneration, Department of Physiology and Cell Biology, Graduate School of Medicine, Kobe University, 7-5-1, Kusunokicho, Chuo-ku, Kobe 650-0017, Hyogo, Japan. E-mail: enomotoh@med.kobe-u.ac.jp.

M. Nagashimada's present address: Department of Cell Metabolism and Nutrition, Brain/Liver Interface Medicine Research Center, Kanazawa University, Kanazawa, Japan.

DOI:10.1523/JNEUROSCI.2079-13.2013

Copyright $\odot 2013$ the authors $\quad 0270-6474 / 13 / 3316372-11 \$ 15.00 / 0$ response to a single growth factor. In mice, vagal neural crest (NC) cells enter the foregut at embryonic day (E) 9.5 (Durbec et al., 1996) and migrate caudally until they colonize the entire length of the gut, at $\sim$ E14. After colonization, the majority of ENS precursors form the myenteric ganglia (MGs), while a subset of ENS precursors undergoes radial migration from the myenteric to the submucosal layer to form the submucosal ganglia (SMGs) (Gershon et al., 1993). Most MG precursors become postmitotic by birth, but some SMG precursors proliferate until postnatal day 15 (P15; Pham et al., 1991). Thus, ENS precursors forming the SMGs remain in an immature state for a long period of time.

Glial cell line-derived neurotrophic factor (GDNF) is expressed in the gut mesenchyme (Young et al., 2001; Natarajan et al., 2002), binds preferentially to GDNF family receptor $\alpha 1$ (GFR $\alpha 1$ ), and activates the RET tyrosine kinase (Jing et al., 1996; Baloh et al., 2000), which is expressed in ENS precursor cells (Pachnis et al., 1993; Durbec et al., 1996; Young et al., 2003). As GDNF signaling is required for ENS precursor proliferation and migration (Chalazonitis et al., 1998; Hearn et al., 1998; Heuckeroth et al., 1998; Taraviras et al., 1999; Gianino et al., 2003; Uesaka et al., 2007), null mutations of Gdnf, Gfr $\alpha 1$, or Ret cause intestinal aganglionosis in mice (Schuchardt et al., 1994; Moore et al., 1996; Pichel et al., 1996; Sánchez et al., 1996; Cacalano et al., 1998; Enomoto et al., 1998). Interestingly, ENS precursors retain responsiveness to GDNF signaling even after birth (Wang et al., 2010), suggesting a role for GDNF in regulating precursor behaviors during both embryonic and postnatal ENS development. 
Here, we demonstrate that GDNF signaling is essential for both primary rostrocaudal and secondary radial migration of ENS precursors, establishing that GDNF has a long-term impact on the driving force of ENS precursor migration. Interestingly, ENS precursors retained in the MGs exhibit minimal activation of MAPK in response to GDNF, suggesting that limited availability of GDNF is crucial for the maintenance of the immature state in ENS precursors. Consistent with this notion, we provide evidence that ENS precursors maintain their undifferentiated state in vivo when GDNF signaling is abrogated in those cells during midgestation. Our data modify our current understanding of the mechanism by which a single neurotrophic factor can regulate precursor cell expansion and differentiation during normal and abnormal ENS development.

\section{Materials and Methods}

Animals. Gfraf ${ }^{f l(G F P)}$ (Uesaka et al., 2007), Ret ${ }^{f l(C F P)}$ (Uesaka et al., 2008), $\operatorname{Ret}^{\text {CreERT2 }}$ (Luo et al., 2009), and Ret ${ }^{B c l-x L}$ (Uesaka and Enomoto, 2010) mice were generated as previously described. Heterozygous mice harboring Gfral green fluorescent protein (GFP) knock-in $\left(G f r \alpha 1^{G F P /+}\right)$ or Ret cyan fluorescent protein (CFP) knock-in alleles $\left(\operatorname{Ret}^{\mathrm{CFP} /+}\right)$ were obtained by crossing Gfral $1^{f l(G F P)}$ or $\operatorname{Ret}^{f(C F P)}$ mice to $\beta$-actin::Cre mice (ACTB::Cre, Jackson Laboratories; Lewandoski et al., 1997). For timespecific inactivation of Gfr $\alpha 1$ or Ret, Gfra $1^{f(\text { GFP })}$ or $\operatorname{Ret}^{f l(C F P)}$ mice were crossed to Gfr $\alpha 1$ heterozygous mice ( $G f r \alpha 1^{+/-}$; Enomoto et al., 1998) or Ret heterozygous mice $\left(\right.$ Ret $^{+/-}$) (Gould et al., 2008) ubiquitously expressing inducible Cre recombinase (CAGGCre-ER, Jackson Laboratories; Hayashi and McMahon, 2002) referred to as CAG::CreER/Gfr $\alpha 1^{+/-}$or $C A G:: C r e E R / R^{2} t^{+/-}$, respectively. Cre activity was induced by a single intraperitoneal injection of 4-hydroxytamoxifen (4-OHT; $0.5 \mathrm{mg}$ per mouse; Sigma) into pregnant mothers. Nrtn (Heuckeroth et al., 1999) or Artn (Honma et al., 2002) heterozygous mice $\left(\mathrm{Nrtn}^{+/-}\right.$or $\mathrm{Artn}^{+/-}$) were generously provided by J. Milbrandt (Washington University, St. Louis, MO). Gdnf facZ mice (Moore et al., 1996; a kind gift from V. Pachnis, MRI-NIMR, London, UK) were used to track expression of GDNF in the gastrointestinal tract by $\beta$-galactosidase ( $\beta$ gal) immunostaining. Mice of either sex were used in this study.

Immunostaining. Tissues were fixed with $4 \%$ paraformaldehyde in $1 \times$ PBS containing $10 \mathrm{~mm}$ phosphate buffer, $\mathrm{pH}$ 7.4, $137 \mathrm{~mm}$ sodium chloride, and $2.7 \mathrm{~mm}$ potassium chloride. Fetuses or dissected gut were fixed from $2 \mathrm{~h}$ to overnight at $4^{\circ} \mathrm{C}$, whereas cultures were fixed for $20 \mathrm{~min}$ at ambient temperature. For preparations of E10.5-E15.5 gut, the entire intestinal tract was fixed intact and processed for immunohistochemistry. For E16.5 and older animals, the small intestine was opened and pinned flat before fixation. After brief fixation, the muscle layers were removed. For frozen sections, fixed preparations were cryoprotected $\left(15 \%\right.$ sucrose at $\left.4^{\circ} \mathrm{C}\right)$, embedded in O.C.T. Compound (Sakura Finetek), frozen, and cryosectioned. For whole-mount staining, the preparations were incubated in $1 \%$ Triton X-100 for 30 min before immunostaining. Immunostaining was performed as described previously (Enomoto et al., 1998), except for anti-GDNF antibody immunostaining. Immunostaining of anti-GDNF antibody was performed without any detergents to avoid the diffusion of antigens. The following antibodies were used: rabbit anti-PGP9.5 (1:1000; Ultra Clone); goat anti-Sox10 (1:400, Santa Cruz Biotechnology); mouse anti-TuJ1 (1:500; Covance); goat anti- $\beta$ galactosidase (1:400; Biogenesis); rabbit anti-phospho-ERK1/2 (1:500; Cell Signaling Technology); and rabbit anti-GDNF (1:200; Santa Cruz Biotechnology). We also used a chicken anti-GFP (1:1000; Aves Laboratories), which can recognize variants of GFP such as CFP and YFP. Secondary antibodies used were DyLight 488 (1:500; Thermo Scientific), and Alexa Fluor 488, 594, or 647 (1:500, Invitrogen). Fluorescent imaging was performed using a Zeiss Axioskop 2FS plus system. Confocal images were acquired using a LSM5 PASCAL system (Carl Zeiss). ImageJ (US National Institutes of Health) was used to measure fluorescence intensities of Alexa Fluor 594 antibody [phospho-ERK (pERK)] in each cell.

Gut organ culture. One day after administration of 4-OHT at E10.5, the gastrointestinal tract was dissected from each fetus and placed in tissue culture medium [DMEM containing 10\% fetal calf serum (FCS), $2 \mathrm{~mm}$ glutamine, and $100 \mathrm{IU} / \mathrm{ml}$ penicillin $/ 100 \mu \mathrm{g} / \mathrm{ml}$ streptomycin] at $37^{\circ} \mathrm{C}$ with $5 \% \mathrm{CO}_{2}$. Gut organ was cultured in the presence of bovine serum albumin (BSA) or GFR $\alpha 1-F c$ (500 ng/ml; R\&D Systems) and/or GDNF (50 ng/ml; R\&D Systems) before fixing.

Time-lapse imaging. Embryonic gut from Gfr $\alpha 1^{f l(G F P) /+} / C A G:: C r e E R$ (control) and Gfr $\alpha 1^{f l(G F P) /-} / C A G:: C r e E R$ (conditional knock-out) fetuses was dissected and attached to a thin strip of filter membrane (HABG047S0, Merck Millipore) by pressing a piece of mesentery to the membrane strip with the tips of forceps. The filter membrane was floated tissue-side down on a $27 \mathrm{~mm}$ coverslip window of a glass-bottomed dish to avoid direct contact of the gut tissue with the glass bottom. The gut was cultured in DMEM containing 10\% of FCS and penicillin/streptomycin at $37^{\circ} \mathrm{C}$ with $5 \% \mathrm{CO}_{2}$ in a time-lapse incubator and examined by an inverted fluorescent microscope (Axiovert 200M, Carl Zeiss) with a CCD camera (Axiocam MRm, Carl Zeiss). For time-lapse imaging, GFP images were obtained every $5 \mathrm{~min}$ for $4-28 \mathrm{~h}$.

Statistical analysis. Statistical analysis was performed using a $t$ test with Welch's correction and Mann-Whitney $U$ test. Results are expressed as the mean \pm SEM.

\section{Results}

\section{GDNF is required for ENS precursor migration to form both} the myenteric and submucosal plexus

To investigate the physiological role of GDNF in ENS precursors during formation of the MGs and SMGs in vivo, Gfro $1^{f l(G F P)}$ mice, in which the expression of Gfrolcan be replaced by the expression of GFP (Uesaka et al., 2007), were crossed to Gfr $\alpha 1^{+/-}$ mice (Enomoto et al., 1998) harboring the CAG::CreER transgene to obtain Gfr $\alpha 1^{f l(G F P) /+} / C A G:: C r e E R$ (control) or conditional knock-out (cKO) embryos in the same litters. In these conditional mouse lines, a chimeric Cre protein fused to the mutated ligand-binding domain of the estrogen receptor is expressed ubiquitously, and treatment of pregnant mothers with 4-OHTinduced Cre activity in utero. We inactivated Gfr $\alpha 1$ at E10.5 and analyzed early gut colonization by ENS precursors (Fig. $1 A$ ). In control embryos, many $\mathrm{GFP}^{+}$cells reached the ileocecal junction, whereas they colonized only the middle portion of the midgut in cKO fetuses (Fig. $1 B$ ). We confirmed that $\mathrm{GFP}^{+}$cells in the migratory wavefront were Sox $10^{+}$ENS precursors, most of which are undifferentiated (Young et al., 2004; Fig. 1C). By timelapse imaging, we compared migratory behaviors between control and cKO ENS precursors. In control gut, $\mathrm{GFP}^{+}$ENS precursors undergoing dynamic movement near the ileocecal junction exhibited polarized morphology and migrated with cyclic motions; that is, the protrusion of the leading edge was followed by a subsequent cell body translocation (Fig. 1D, top panels). Gfr 1 cKO ENS precursors also exhibited polarized morphology similar to that of control cells. In contrast, the motility of the cell body was slowed in cKO ENS precursors (Fig. 1D, bottom panels). We found that the average velocity of the cell movement decreased significantly in cKO fetuses (control, $57.4 \pm 4.8 \mu \mathrm{m} / \mathrm{min}, n=18$ cells; $\mathrm{cKO}, 13.5 \pm 0.6 \mu \mathrm{m} / \mathrm{min}, n=$ 16 cells; $p<0.05$, unpaired $t$ test with Welch's correction). These results indicate that GDNF signaling is essential for the enhancement of ENS precursor migration.

ENS precursors complete rostrocaudal migration across the entire gut until E14.5. After the formation of the MGs, inward migration of ENS precursors occurs, giving rise to the SMGs (Fig. $1 E)$. To address the question of whether GDNF also controls radial migration of ENS precursors, we first examined the expression of Gfr $\alpha 1$ in ENS precursors undergoing radial migration by using Gfr $\alpha 1^{G F P /+}$ mice, which express GFP under the control of endogenous Gfr $\alpha 1$ promoter (Uesaka et al., 2007). We confirmed that Sox $10^{+}$ENS precursors in the submucosal region expressed 
Gfro1 at E16.5 (Fig. 1F), suggesting that the GDNF signal may be also required for radial migration of ENS precursors. We therefore inactivated Gfr $\alpha 1$ at E15.5, and the submucosal region was analyzed at E18.5 by whole-mount immunostaining against GFP and PGP9.5 (Fig. 1G). In control fetuses, many $\mathrm{GFP}^{+}$neurons were observed in the submucosal region (Fig. $1 \mathrm{H}$, left). In contrast, very few submucosal neurons were detected in cKO fetuses (Fig. $1 H$, right; control, $394.4 \pm 10.8$ cells/ $\mathrm{mm}^{2}, n=3$; and $G$ fr $\alpha 1 \mathrm{cKO}, 132.5 \pm 15.1$ cells $/ \mathrm{mm}^{2}, n=3 ; p<0.001$, unpaired $t$ test with Welch's correction). The impairment of SMG formation was not rescued by elevated expression of $B c l-x L$ (Fig. $2 A, B)$, which allows Ret-deficient enteric neurons to survive in vivo (Uesaka and Enomoto, 2010), suggesting that the lack of submucosal neurons in cKO fetuses was not due to cell death.

To confirm whether ENS precursors in the MGs invade the submucosal region in a GDNF-dependent manner, we labeled SMG precursors and neurons transiently and genetically by crossing Gfr $\alpha 1^{f l(G F P) /+}$ / $\operatorname{Ret}^{f^{l(C F P) /+}}$ mice with $\operatorname{Ret}^{\mathrm{CreERT2/+}}$ mice (Luo et al., 2009) (Fig. 3A). The Ret ${ }^{C r e}$ $E R T 2 /+$ system provides more precise information about the cell fate of labeled ENS precursors, as this had undetectable background recombination activity without 4-OHT (data not shown). After Cremediated activation of GFP expression at E13.5, GFP-labeled cells were analyzed at E14.5 and E18.5 (Fig. 3B). At E14.5 in control (Gfr $\left.\alpha 1^{f l(G F P) /+} / \operatorname{Ret}^{\mathrm{CreERT2/+}}\right) \mathrm{em}-$ bryos, $20.1 \pm 5.5 \%(n=3)$ of GFPlabeled ENS cells in the MGs did not yet express a neuronal marker, PGP9.5 (Fig. $3 C$, top). At E18.5, most $\mathrm{GFP}^{+}$cells were detected as PGP9. $5^{+}$neurons in both the MGs and the SMGs (Fig. 3D, top), indicating that GFP-labeled ENS precursors migrate from the MGs to the submucosal layer and differentiate into neurons. Similarly, we examined the cell fates of ENS precursors lacking RET activity. In Ret cKO $\left(\right.$ Ret $\left.^{f l(C F P) / C r e E R T 2}\right)$ mice, $24.5 \pm 2.9 \%$ $(n=3)$ of $\mathrm{GFP}^{+}$cells in the MGs were PGP9.5 ${ }^{-}$cells at E14.5 (Fig. 3C, bottom), and then at E18.5 GFP-labeled cKO cells

failed to invade into the submucosal region and were retained in the MGs (Fig. 3D, bottom panels). These data suggest that RET signaling is essential for radial migration of ENS precursors from the MGs to the submucosal layer.

GDNF is likely to be a primary ligand for the GFR $\alpha 1 /$ RET receptor complex on ENS precursors, as it binds with the highest affinity to the GFR $\alpha 1$ and $G d n f^{+/-}$mice have fewer submucosal neurons (Gianino et al., 2003). However, there is also weak cross talk in vitro between GFR $\alpha 1$ and other GDNF family ligands (GFLs), neurturin (NRTN), and artemin (ARTN;

$\mathbf{E}$

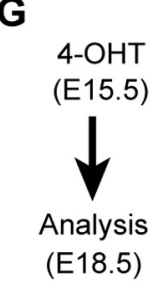
$\mu \mathrm{m} ; \boldsymbol{F}, \boldsymbol{H}, 20 \mu \mathrm{m}$.
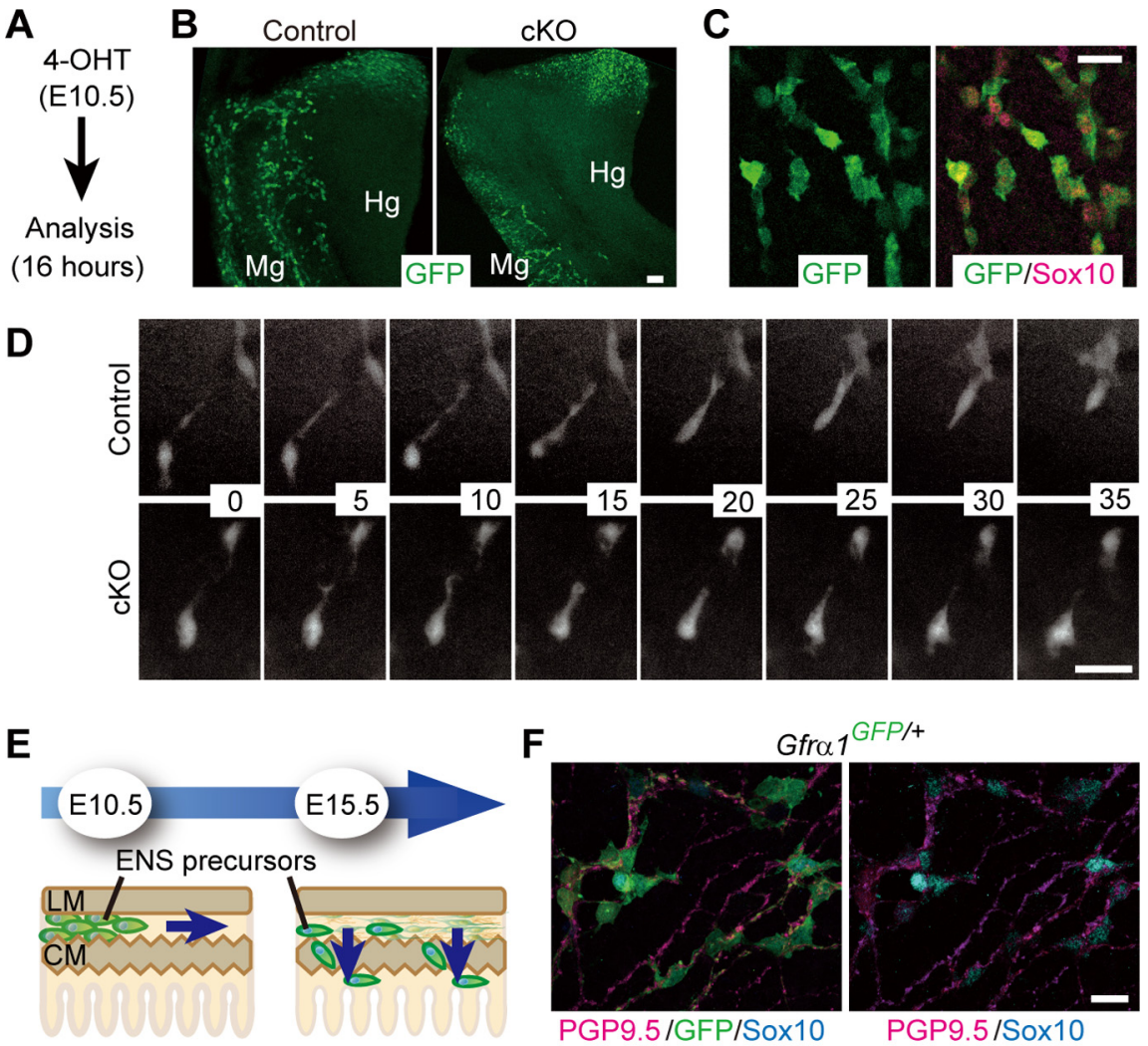

PGP9.5/GFP/Sox10

PGP9.5/Sox10
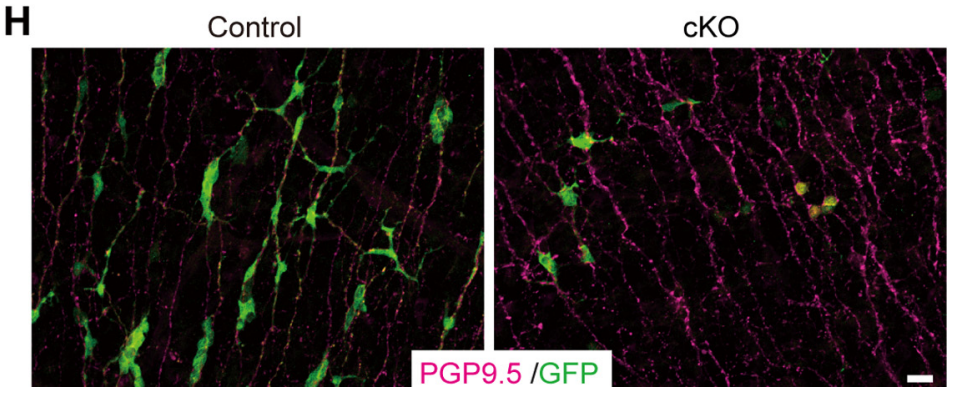

Figure 1. GDNF is essential for ENS precursor migration to form both the MGs and SMGs. A, 4-OHT was administrated to pregnant females at E10.5. Embryonic guts were dissected out from control and Gfr $\alpha 1 \mathrm{CKO}$ fetuses $16 \mathrm{~h}$ after injection of 4-0HT, and were cultured in the time-lapse incubator. $\boldsymbol{B}_{,} \mathrm{GFP}^{+}$cells (green) in the gut of control and Gfr $\alpha 1$ cKO fetuses $16 \mathrm{~h}$ after treatment with 4- $\mathrm{OHT}$. In the control fetuses, $\mathrm{GFP}^{+}{ }^{+}$cells entered the hindqut, whereas inactivation of $\mathrm{Gfr} \alpha 1$ impaired colonization of the gut by ENS precursors. C, Whole-mount GFP (green) and an ENS precursor marker, Sox10 (magenta), staining of ENS precursors in the migratory wavefront along the gut from the control fetuses. GFP ${ }^{+}$cells coexpressed Sox 10 , indicating immature ENS precursors. D, Selected frames from time-lapse fluorescent imaging for the migration of GFP-labeled ENS precursors from control and Gfr $\alpha 1 \mathrm{CK} 0$ explants. Images were acquired at $5 \mathrm{~min}$ intervals. $E$, Schematic diagram showing rostral-to-caudal colonization of the midgut by ENS precursors and secondary inward migration toward the submucosal region. $\boldsymbol{F}$, Histological analysis Gfr $\alpha 7^{G F P /+}$ SMGs showing Gfr $\alpha 1$ expression (as revealed by GFP, green) in Sox $10^{+}$ENS precursors (blue) and PGP9.5 neurons (magenta). $\mathbf{G}$, Control and Gfr $\alpha 1$ CKO fetuses were subjected to 4-OHT treatment at E15.5. $\boldsymbol{H}$, Whole-mount GFP (green) and PGP9.5 (magenta) staining of the SMGs in the small intestine from E18.5 control and Gfr $\alpha 1$ cKO fetuses. Scale bars: $\boldsymbol{B}-\boldsymbol{D}, 50$

Airaksinen and Saarma, 2002), and $\mathrm{Nrtn}^{-1-}$ mice have 35\% fewer submucosal neurons in the small intestine (Gianino et al., 2003). To examine the possibility that NRTN or ARTN contributes to radial migration of ENS precursors, we analyzed Nrtn- and Artn-deficient mice (Heuckeroth et al., 1999; Honma et al., 2002). Mice deficient for these GFLs showed early SMG formation with no apparent developmental abnormalities (Fig. 4A, B), indicating that neither NRTN nor ARTN are implicated in radial migration of ENS precursors. Altogether, these data indicate that a GDNF-GFR $\alpha 1 /$ RET signal- 
A
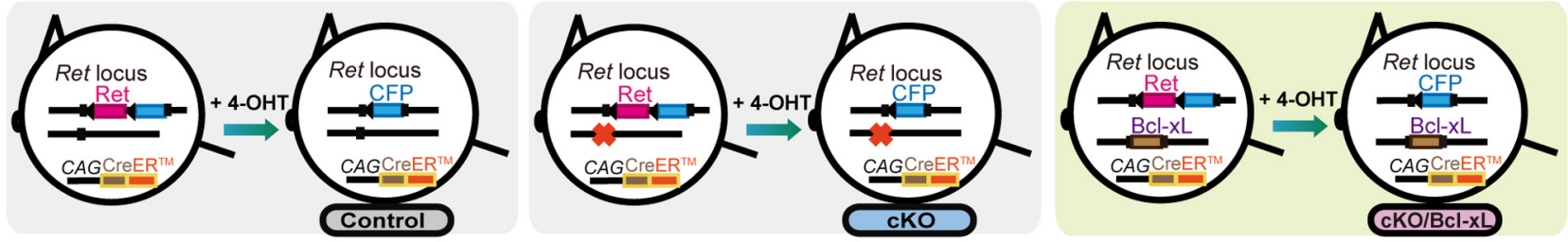

B

Control

cKO
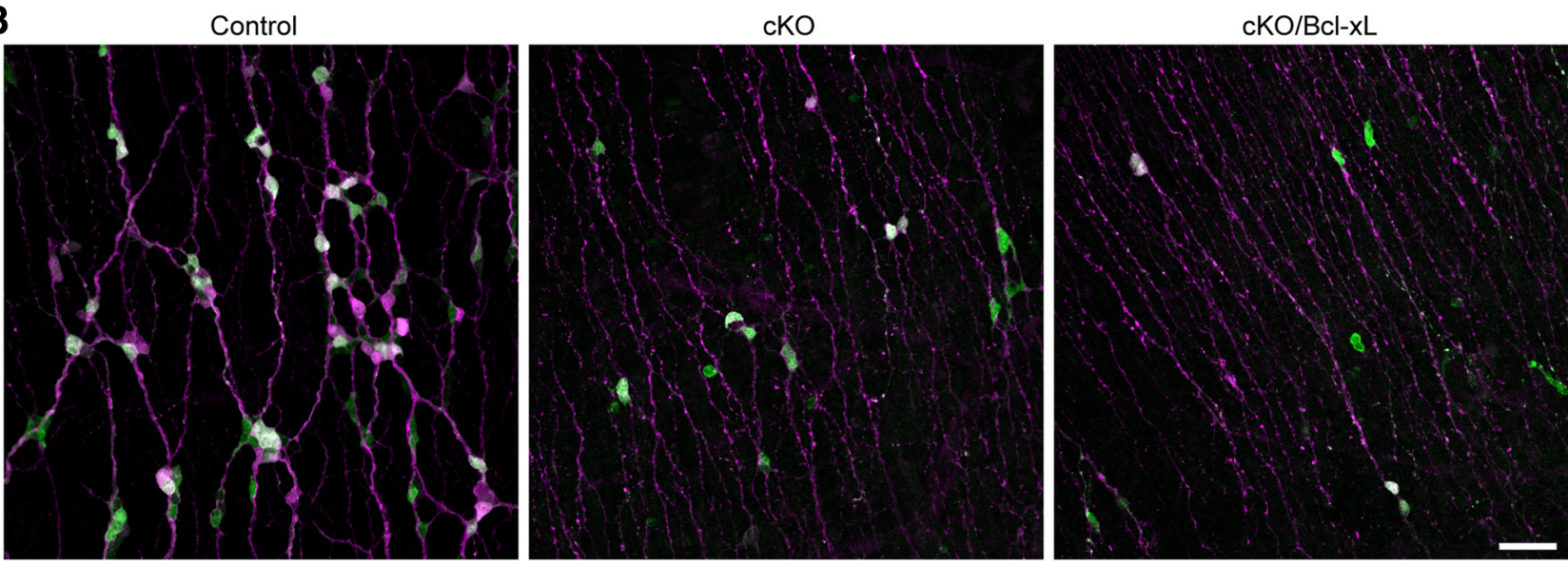

PGP9.5/GFP

Figure 2. Elevated expression of $\mathrm{BCl}-\mathrm{xL}$ fails to rescue impaired formation of the submucosal plexus induced by conditional Ret inactivation. $A$, Schematic diagram showing the strategy of Ret conditional knockout with elevated expression of BCl-xL in ENS cells. To explore the possibility that impaired formation of submucosal neurons can be explained by cell survival defects, we used Ret- $B C l-x L$ knock-in mice, in which Ret-deficient enteric neurons can survive. The Ret- $B C l-x L$ allele contains the wild-type human $B C l-x L C D N A$ (brown boxes) under the endogenous Ret promoter.

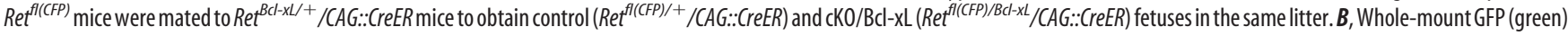
and PGP9.5 (magenta) staining of the SMGs in the small intestine from E18.5 control, $\mathrm{CKO}$, and CKO/BCl-xL fetuses. These fetuses were subjected to 4-0HT treatment at E15.5 to inactivate Ret. Scale bar, $50 \mu \mathrm{m}$.

ing cascade is essential for triggering both the primary and secondary migration of ENS precursors to form the MGs and the SMGs, respectively.

\section{GDNF expression shifts to the submucosal side of circular muscle layers}

Although GDNF expression in the gut mesenchyme persists throughout development, changes in the levels of GDNF expression have been reported during gut colonization by ENS precursors (Golden et al., 1999; Natarajan et al., 2002). Since secondary migration of ENS precursors to the submucosal layer is also triggered in response to GDNF, we examined $G d n f$ expression pattern during formation of the SMGs in the small intestine by detecting $\beta$ gal in $G d n f^{\text {lac } /+}$ mouse gut (Moore et al., 1996) and with specific anti-GDNF antibody. During the rostral-to-caudal migration of ENS precursors along the gut, high $\beta$ gal immunoreactivity was observed in the outer gut mesenchyme (Fig. 5A). After formation of the MGs, the expression of $\beta$ gal in the muscle layers was reduced in the small intestine. At this stage, $\beta$ gal immunoreactivity was detected in the submucosal side of circular muscle layers (Fig. $5 B$, top). GDNF immunostaining confirmed that GDNF is relatively abundant in the circular muscle layers (Fig. 5C, top). These specific immunoreactivity patterns were readily distinguished from the nonspecific staining observed in negative controls. In wild-type (WT) mice, $\beta$ gal immunoreactivity was not observed in circular muscle layers (Fig. 5B, bottom), and $G d n f$ deficiency abolished GDNF immunoreactivity in the gut (Fig. 5C, bottom). Changes in GDNF expression pattern prob- ably lead to changes in GDNF availability that influences the cellular response of ENS precursors. GDNF could be crucial to the entire ENS development during early to late gestational stages.

ENS precursors in the myenteric plexus show low activation of RET signaling pathway

ENS precursors are retained in the MG until $\sim$ E15.5, and then begin radial migration toward the submucosal region in response to GDNF. During MG formation, RET is expressed in both ENS precursors and differentiating neurons. To examine the differences in GDNF availability in retained ENS precursors and differentiating neurons during $\mathrm{MG}$ formation, we examined the activation levels of ERK, which is a crucial downstream effector of RET. We used Ret ${ }^{G F P /+}$ gut to visualize ENS precursors and differentiating neurons, and distinguished ENS precursors from differentiating neurons by coexpression of GFP and Sox10. At E12.5, $\mathrm{GFP}^{+}{ }^{-}$Sox $10^{+}$ENS precursors showed low or undetectable levels of ERK phosphorylation (Fig. 6A,B). Similarly, in mitotic ENS precursors, the level of pERK did not change significantly (Fig. 6B). Upregulation of the pERK was mainly seen in $\mathrm{GFP}^{+}$-Sox $10^{-}$differentiating neurons (Fig. $6 A, B$ ). To confirm that upregulated pERK activity in differentiating neurons is a downstream effect in the GDNF-GFR $\alpha 1$ /RET pathway, we examined whether pERK expression diminished when the Gfr $\alpha 1$ gene was deleted in enteric neurons. At E13.5 in Gfr $\alpha 1 \mathrm{cKO}$ midgut $1 \mathrm{~d}$ after treatment with 4-OHT, pERK was detected in $\mathrm{GFP}^{-}-\mathrm{TuJ1}{ }^{+}$neurons (Gfro1-expressing neurons; Fig. 6C, arrows), whereas the level of pERK was significantly reduced in 
$\mathrm{GFP}^{+}-\mathrm{TuJ} 1^{+}$neurons (Gfr $\alpha 1$-deficient neurons; Fig. 6C,D). These results validated ERK activation in neurons as occurring downstream of GDNF-GFR $\alpha 1$ /RET signaling. Our findings suggest that minimal activation of the ERK by GDNF may be crucial for the maintenance of the immature state in ENS precursors.

\section{Lack of GDNF signaling leads to} inhibition of neuronal differentiation and persistence of ENS precursors During formation of the MGs, ENS precursors exhibit a low level of RET/ERK pathway activation. We examined whether the loss of GDNF signaling results in the persistence of ENS precursors in addition to an interruption of their migration. We used $\operatorname{Ret}^{f(C F P) /+} / C A G:: C r e E R$ mice as a control and $\operatorname{Ret}^{f l(C F P) / C r e E R T 2}$ mice as Ret cKO. These animals were treated with 4-OHT at E10.5 and analyzed at E15.5 (Fig. 7A). In the MGs of control midgut $(n=4)$ at E15.5, $32.6 \pm 3.0 \%$ of total $\mathrm{GFP}^{+}$ENS cells coexpressed Sox10, and we also found that ENS cells with relatively strong GFP expression exhibited neurite outgrowth (Fig. $7 B$, left panels). In contrast, inactivation of Ret in ENS precursors at E10.5 resulted in an approximately twofold increase in the population of $\mathrm{GFP}^{+}$ cells coexpressing Sox10 in the MGs of the midgut at E15.5 $($ Ret $\mathrm{cKO}, 69.8 \pm 3.5 \%, n=$ 3; control, $32.6 \pm 3.0 \%, n=4$; Fig. $7 B$, right panels, $D)$. These $\mathrm{GFP}^{+}-$Sox $10^{+}$doublelabeled cells coexpressed the ENS precursor marker Phox $2 b$ (data not shown). We further confirmed that the inactivation of Ret in ENS precursors at E10.5 resulted in a significant decrease in the neuronal population of total $\mathrm{GFP}^{+}$cells at E15.5 (Fig. 7C,D; control, $71.3 \pm 6.6 \%, n=4$; vs $\mathrm{cKO}, 8.6 \pm$ $0.9 \%, n=3 ; p<0.05$, unpaired $t$ test with Welch's correction).

Previous in vitro studies have shown that GDNF promotes neuronal differentiation but not glial differentiation (Chalazonitis et al., 1998). Consistent with this, conditional inactivation of Gfrol at E10.5 led to a significant reduction in the $\mathrm{GFP}^{+}-\mathrm{PGP} .5^{+}$neuron population of total $\mathrm{GFP}^{+}$cells in the midgut at E15.5 (control, $34.1 \pm 5.0 \%, n=7$; vs $\mathrm{CKO}, 19.8 \pm 2.0 \%, n=7 ; p<0.05$, unpaired $t$ test with Welch's correction), but had no impact on glial cell population detected by coexpression of GFP and brain lipid-binding protein (control, $48.7 \pm 2.6 \%, n=3$; vs cKO, $46.7 \% \pm 2.4 \%, n=3$ ). Thus, these data suggest that GDNF signaling is required for neuronal differentiation in vivo. We showed previously that the inactivation of GDNF signaling at E13.5 does not lead to widespread neuronal death in the midgut (Uesaka et al., 2007), although the possibility that a minimal number of neurons may die cannot be excluded. Gfr $\alpha 1$ inactivation also reduced cell proliferation, but Gfro1-deficient ENS precursors still exhibited low proliferative capacity (Uesaka et al., 2007). We found mitotic figures and dividing cells in $\mathrm{GFP}^{+}-$Sox $10^{+} \mathrm{cKO}$ cells at E15.5 (Fig. 7E). Together, our findings suggest that insufficient access to GDNF may lead to the
B

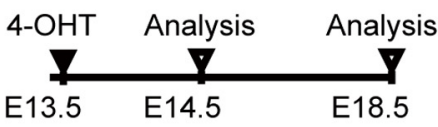

Myenteric plexus

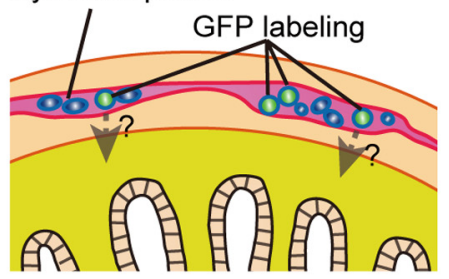

D Myenteric

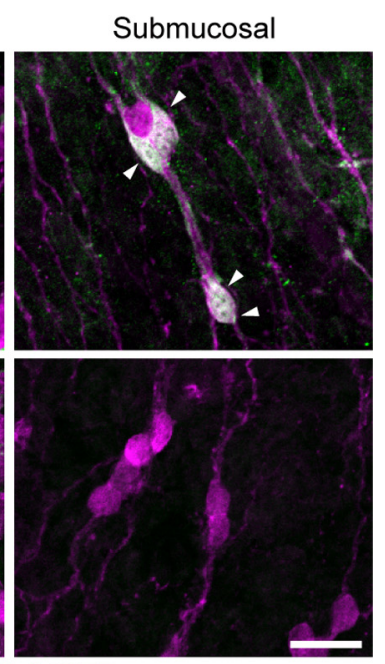

PGP9.5/GFP
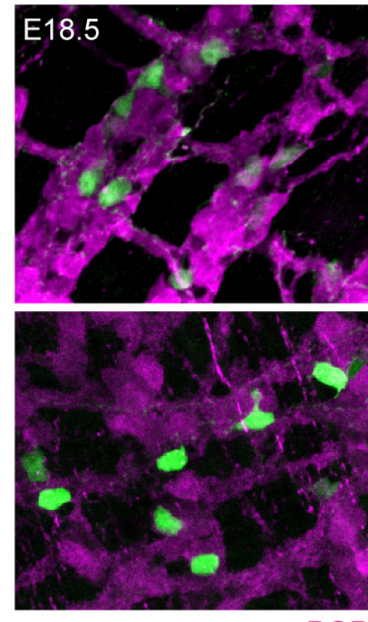

Figure 3. ENS precursors in the MGs invade the submucosal region in a RET-dependent manner. $\boldsymbol{A}$, Schematic diagram showing observed in the myenteric plexus in both control and CKO midgut. D, Immunofluorescence staining for PGP9.5 (magenta) and GFP (green) on control and CKO MGs and SMGs at E18.5. The SMGs in control small intestine contained GFP ${ }^{+}$neurons (arrowheads), whereas Ret cKO mice display no GFP ${ }^{+}$cells in the submucosal region. Scale bar, $50 \mu \mathrm{m}$.

persistence of ENS precursors in the MGs until the developmental stage of the SMGs.

\section{ENS precursors lacking GDNF availability retain migratory and neurogenic potential}

If insufficient access to GDNF does lead to an interruption of ENS precursor migration and neuronal differentiation, then the restoration of GDNF signaling should restart their migration and neuronal differentiation. As soluble GFR $\alpha 1-\mathrm{Fc}$ has been previously shown to activate RET in response to GDNF even in cells lacking endogenous GFR $\alpha 1$ (Yu et al., 1998; Paratcha et al., 2001), we attempted to restore GDNF signaling in Gfro1-deficient ENS precursors in gut organ culture. Control $\left(G f r \alpha 1^{f l(G F P) /+} / C A G:: C r e E R\right)$ and cKO (Gfr $\alpha 1^{f l(G F P) /-} / C A G::$ CreER) embryos were treated with 4-OHT at E10.5, and the entire gut dissected $16 \mathrm{~h}$ later was maintained in organ culture (Fig. $8 A$ ). In control embryos, ENS precursors colonized the entire midgut, whereas Gfr $\alpha 1$-deficient ENS precursor failed to reach the cecum (Fig. $8 B$ ). The entire gut of $G f r \alpha 1 \mathrm{cKO}$ embryos was 
A

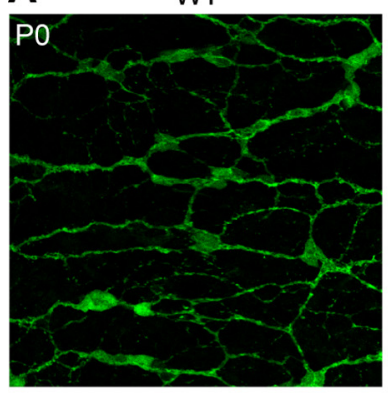

B

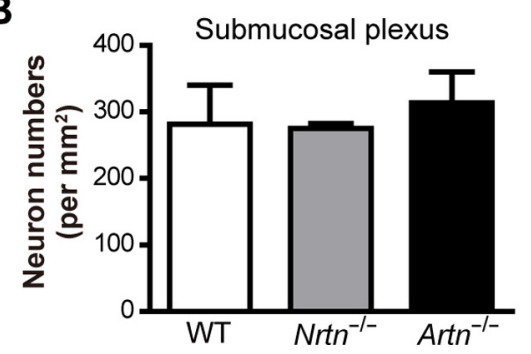

Figure 4. NRTN and ARTN signals are dispensable for radial migration of ENS precursors. A, PGP9.5 (green) staining of the SMGs in PO WT, Nrtn ${ }^{-1-}$, and Artn $^{-1-}$ mice. B, Quantification of submucosal neurons in the middle portion of the small intestine of WT, Nrtn ${ }^{-1-}$, and Artn ${ }^{-1-}$ mice at PO. Because GFR $\alpha 1 /$ RET receptor complex mainly mediates GDNF signaling, and because Nrtn- or Artn-deficient mice display no apparent deficits in the formation of submucosal neurons, the ligand that associates with the GFR $\alpha 1 /$ RET signaling cascade for the formation of the SMGs is likely to be GDNF. Scale bars, $20 \mu \mathrm{m}$.

placed in organ culture medium with vehicle (BSA) or soluble GFR $\alpha 1$-Fc and incubated for $16 \mathrm{~h}$. Although the impaired migration of ENS precursors was not improved in the gut cultured with vehicle (BSA), soluble GFR $\alpha 1$-Fc could partly restore a rostralto-caudal migration and neuronal differentiation (Fig. $8 C$ ), suggesting that ENS precursors that failed to migrate due to insufficient access to GDNF can maintain migration potential in response to GDNF signaling. We further examined whether GDNF signal recovery could restore neuronal differentiation of ENS precursors $4 \mathrm{~d}$ after inactivation of Gfr 1 in gut explant culture (Fig. 8D). In cKO explants, $\mathrm{GFP}^{+}$ENS cells lacking Gfr $\alpha 1$ aggregated into clumps, and $\mathrm{TuJ} 1^{+}$neurons were sparse. These findings suggest that migration and neuronal differentiation of ENS precursors were repressed by the lack of GDNF signaling. Subsequently, BSA and GDNF were administered, but these treatments had no impact on neuronal differentiation of Gfr $\alpha 1$ deficient ENS cells (Fig. 8E, top panels). In contrast, soluble GFR $\alpha 1-F c$ and GDNF treatment restored migration of $\mathrm{GFP}^{+}$cells from the high-density region and induced neuronal differentiation of $\mathrm{GFP}^{+}$precursors surrounding the high-density region (Fig. 8E, bottom panels). We found a significant increase in $\mathrm{GFP}^{+}$neuron numbers in Gfr $\alpha 1$ cKO gut after treatment with GDNF and GFR $\alpha 1$-Fc (Fig. $8 F$ ), suggesting that Gfr $\alpha 1$-deficient ENS precursors retain the potential to differentiate into neurons. Altogether, these findings support the idea that insufficient activation of GDNF signaling leads to the pausing state of ENS precursors during MG development.

\section{Discussion}

Our study provides evidence that GDNF signaling regulates the development of the SMGs at least in part by promoting radial migration of ENS precursors. During midgestation (E13.5E15.5), premigratory SMG precursors are located in the myenteric layer and are surrounded by neuronally differentiating cells destined to form the MGs. Because SMG development occurs substantially later than MG development (Gershon et al., 1993), SMG precursors must remain in an immature state for a longer period than do MG precursors. Our immunohistochemical analysis revealed that premigratory SMG precursors exhibit low levels of ERK phosphorylation, suggesting that suppressing the full activation of ERK is required for the maintenance of the immature state in ENS precursors. The availability of GDNF is limited in vivo (Shen et al., 2002; Gianino et al., 2003), which can be disadvantageous, as any defects that affect GDNF signaling may confer susceptibility to Hirschsprung disease. We speculate, however, that limited GDNF availability is important for normal ENS development, as it seems to play a role in maintaining ENS precursors in the immature state for the long term. Thus, the development of the ENS is regulated by exquisite control of GDNF signaling.

GDNF is essential to drive rostrocaudal and radial migration of ENS precursors Previously reported in vitro studies have shown that GDNF is chemoattractive to ENS precursors (Young et al., 2001; Natarajan et al., 2002), suggesting that GDNF is required for the directional migration of ENS precursors toward the caudal end of the small intestine and for retaining ENS precursors within the gut wall. Our finding is that GDNF is required to drive ENS precursor migration in vivo, and thus ENS precursors lacking GDNF are retained within the gut wall. ENS precursor migration activities depend on the activation level of RET, as reduction in Ret expression to $\sim 30 \%$ of normal level, which does not affect proliferation (Nishiyama et al., 2012), and survival of ENS precursors (Uesaka and Enomoto, 2010) result in the delay of gut colonization by ENS precursors, implying that ENS precursors with sufficient access to GDNF can continue to migrate selectively at the migratory wave front.

We further demonstrate that GDNF is also essential for triggering secondary inward migration of ENS precursors toward the submucosal region. Netrin-mediated guidance has previously been implicated in the radial migration of ENS precursors (Jiang et al., 2003). While GDNF signaling is essential for triggering radial migration of ENS precursors (Figs. 2, 3), netrins likely cooperate to promote radial migration as guidance cues.

Gfr $\alpha 1$ cKO ENS precursors exhibit a polarized morphology, that is, extension of the leading process, whereas the motility of the cell body is slowed. Similar impairment of neuronal migration has been observed in precursors of GABAergic interneurons deficient in Rho-regulated active nucleators mammalian diaphanous homolog 1 (mDial) and mDia3 (Shinohara et al., 2012). The Rho signaling via $\mathrm{mDia}$ and Rho-associated protein kinase (ROCK) is one of the candidate signaling pathways that have been suggested to regulate ENS precursor migration in response to GDNF. For instance, the phosphorylation of the serine residue at codon 696 (S696) of human RET is required for GDNFmediated activation of RAC1-guanine nucleotide exchange factor in vitro (Fukuda et al., 2002), and RET S697A mutant mice (corresponding to S696 in human RET) show a migration defect of ENS precursors (Asai et al., 2006). Moreover, the inhibition of 


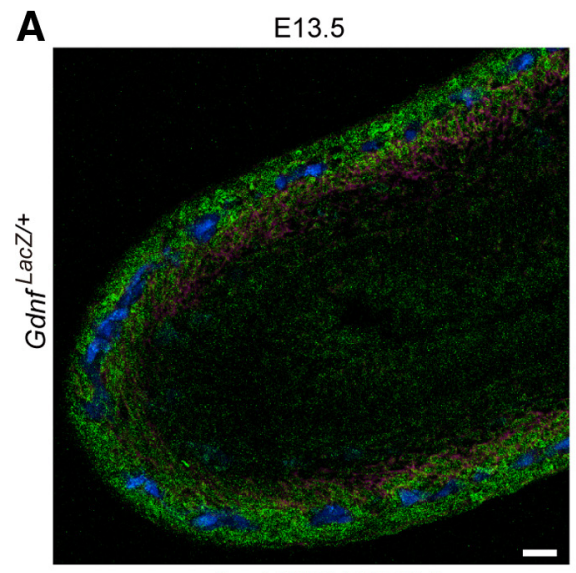

Bgal/SMA/PGP9.5
B
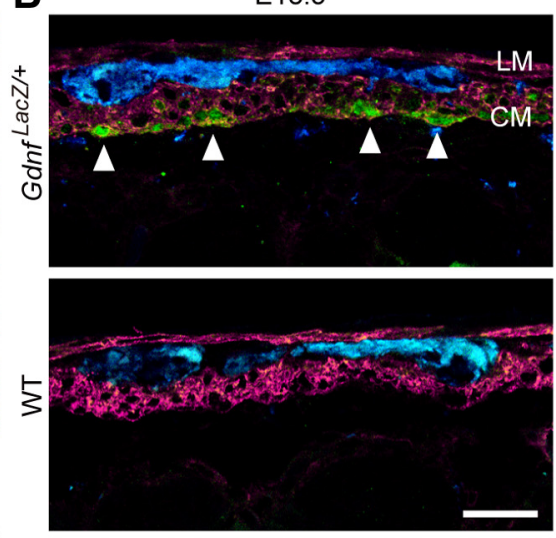

Bgal/SMA/PGP9.5
C
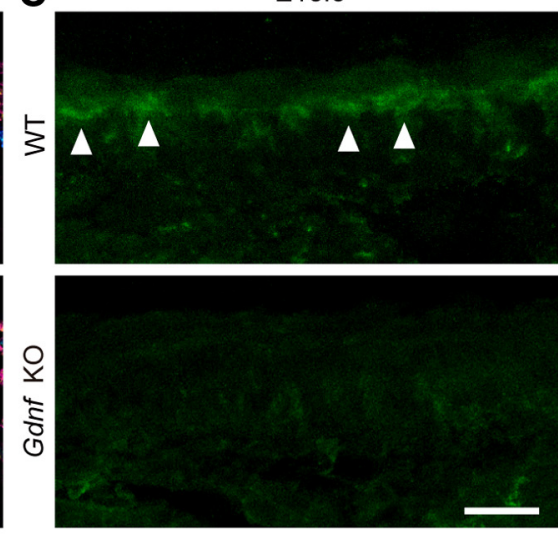

GDNF

Figure 5. GDNF expression shifts to the submucosal side of the circular muscle layers. A, GDNF expression in the midgut at E13.5. Intestinal sections from Gdnf fazl/+ embryos were stained with $\beta g$ al (green), PGP9.5 (blue), and smooth muscle actin (SMA; magenta) antibodies. During the rostro-to-caudal migration of ENS precursors along the midgut, high $\beta$ gal immunoreactivity was observed in the outer gut mesenchyme. B,GDNF expression shift to the submucosal region after formation of the MGs in the small intestine atE18.5. Bgal immunoreactivity (arrowheads) was detected in the submucosal side of circular muscle layers in the small intestine from Gdnfozl/+ mice. In negative control (WT mice), $\beta$ gal immunoreactivity was not observed in circular muscle layers. C, GDNF immunostaining at E18.5 (green) confirmed that GDNF is relatively abundant in the circular muscle layers. In negative controls (GdnfKO mice), GDNF immunoreactivity was not observed in circular muscle layers. LM, Longitudinal muscle layer; CM, circular muscle layer. Scale bars, $50 \mu \mathrm{m}$.

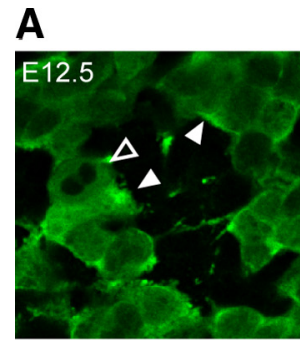

GFP

C

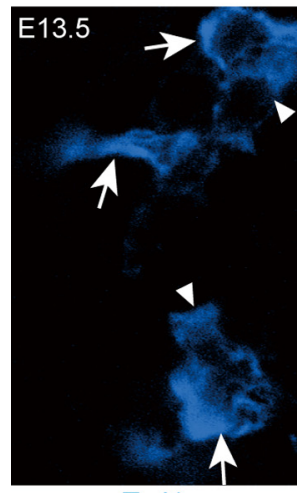

TuJ1

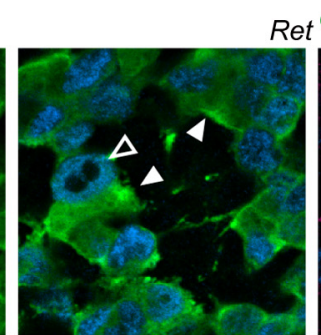

GFPISOx10
$\operatorname{Ret}^{G F P /+}$

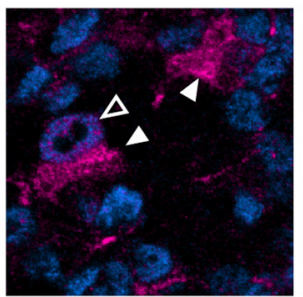

pERK/SOX10

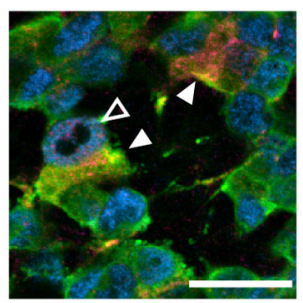

GFP/pERK/Sox10
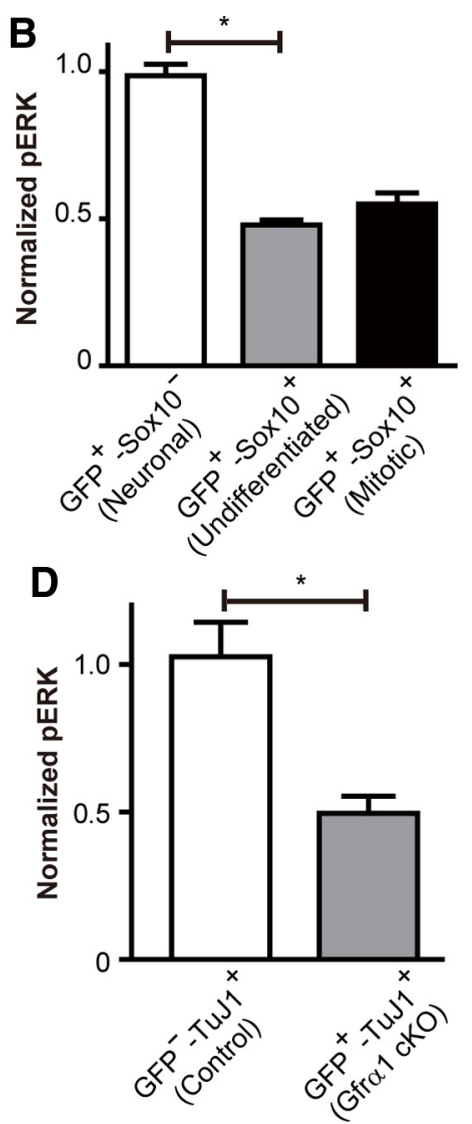

Figure 6. ENS precursors in the MGs show lowactivation of RET signaling pathway.A, Immunohistochemical staining for GFP, Sox10, and MAPK (pERK) pathways in E12.5 Ret fFP/+ midgut.Phosphorylation of ERK was mainly observed in GFP ${ }^{+}$-Sox $10^{-}$-differentiating neurons (arrowheads) but not in GFP ${ }^{+}$-Sox $10^{+}$ENS precursors. B, Quantification of pERK immunofluorescence from GFP ${ }^{+}$-Sox $10^{-}$neuronal lineage cells $(n=20)$, GFP $^{+}$-Sox $10^{+}$undifferentiated cells $(n=20)$ or mitotic GFP ${ }^{+}-$Sox $10^{+}$cells (open arrowheads, $\left.n=11\right)$. Values arenormalized to GFP ${ }^{+}-$Sox $10^{-}{ }^{*}{ }^{*} p<0.05$, unpaired ttest with Welch's correction. Error bars represent SEM. C, Downregulation of pERK in Gfr $\alpha 1$-deficient enteric neurons. Activation of ERK (pERK) was detected in GFP ${ }^{-}$-Tu $1{ }^{+}$control neurons (GFP ${ }^{-}$-Tul $1^{+}$, arrows). By contrast, the level of pERK was reduced in Gfr $\alpha 1$ deficient neurons (GFP ${ }^{+}-\mathrm{TU}_{1}{ }^{+}$, arrowheads). D, Quantification of pERK immunofluorescence from control neurons $(n=10)$ or Gfr $\alpha 1$-deficient neurons $(n=10)$. Values are normalized to GFP ${ }^{-}-$Tu $1{ }^{+}$. ${ }^{*} p<0.05$, unpaired $t$ test with Welch's correction. Error bars represent SEM. Scale bars:A, $20 \mu \mathrm{m} ; C, 5 \mu \mathrm{m}$.

ROCK suppresses ENS precursor migration in gut explants, and these effects may be RET dependent (Stewart et al., 2007). Further experiments will be needed to determine whether Rho signaling acts downstream of RET in ENS precursor migration.
GDNF is required for triggering neuronal differentiation of ENS precursors

In postmigratory ENS precursors, GDNF signaling promotes neuronal precursor proliferation (Gianino et al., 2003; Wang et 

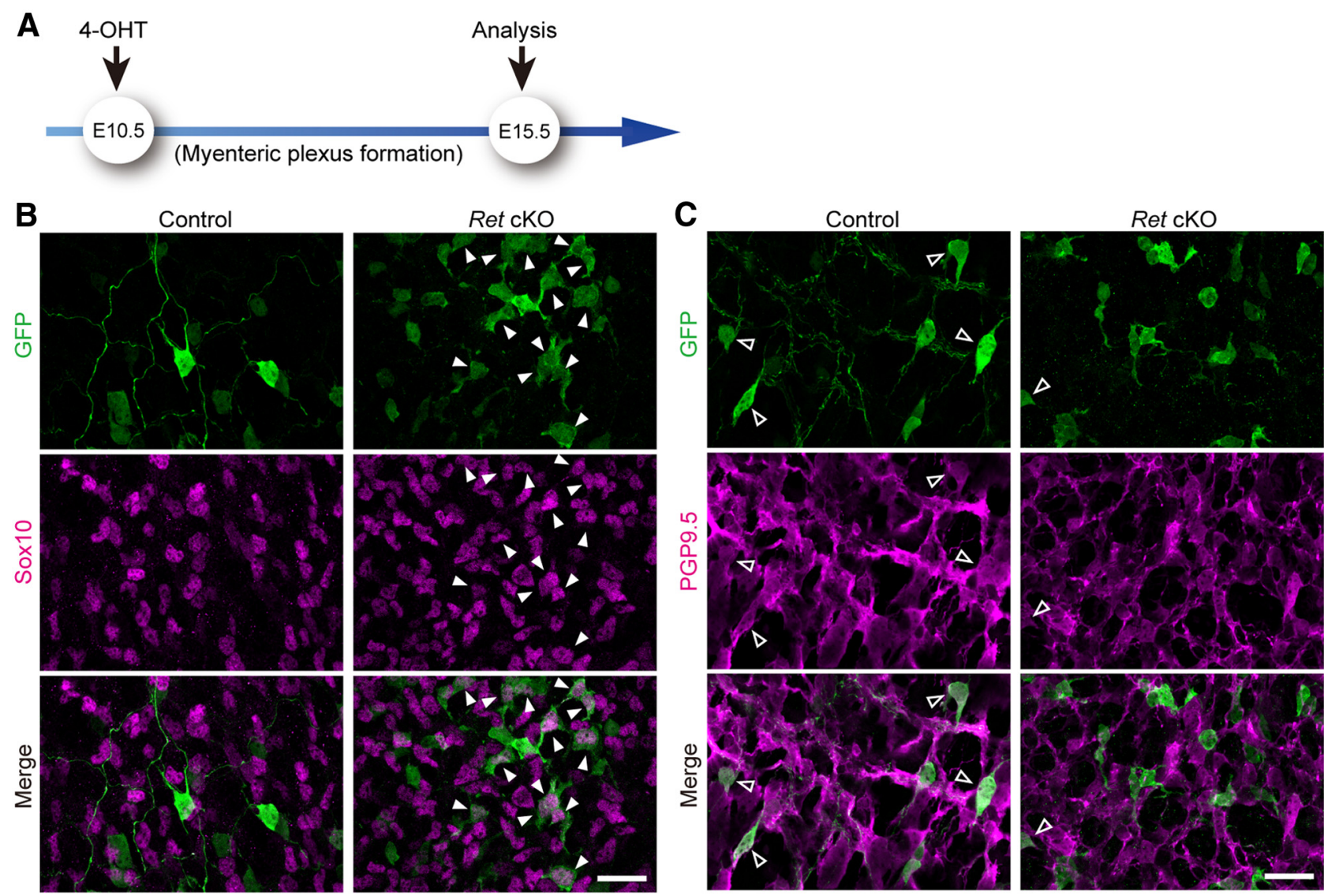

D

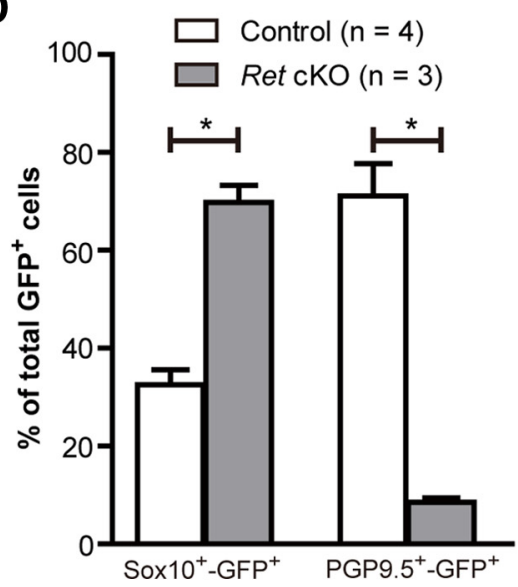

$\mathbf{E}$

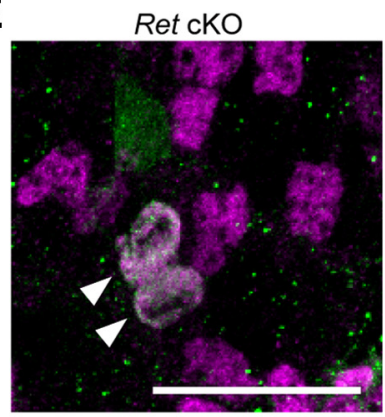

GFP/Sox10

Figure 7. The lack of GDNF availability leads to the inhibition of neuronal differentiation and persistence of ENS precursors. $A$, Embryonic midgut was dissected out from E15.5 control and Ret cKO fetuses in which Ret inactivation was induced at E10.5. B, Colabeling with GFP (Ret) and Sox 10 to distinguish undifferentiated cells (GFP ${ }^{+}{ }_{-S 0 x 10^{+}}$cells) from glial lineage cells (Sox10 ${ }^{+}$cells) and neuronal lineage cells (GFP ${ }^{+}$cells). In Ret cKO MGs, GFP ${ }^{+}$-Sox $10^{+}$double-positive cells were easily found (arrowheads). C, Neuronal differentiation of control and Ret cKO ENS precursors in the midgut. In controls at E15.5, many GFP ${ }^{+}$cells were labeled by PGP9.5 (open arrowheads), but not in CKO MGs. D, Quantification of the fraction of GFP ${ }^{+}-$Sox $10^{+}$double-positive cells and GFP ${ }^{+}$-PGP9.5 ${ }^{+}$double-positive neurons within the GFP ${ }^{+}$cells in the MGs of E15.5 control $(n=4)$ and Ret cK0 mice $(n=3) .{ }^{*} p<0.05$, unpaired $t$ test with Welch's correction. Error bars represent SEM. E, Dividing cells in Ret cKO GFP ${ }^{+}$cells colabeled by Sox10 at E15.5. Scale bars, $50 \mu \mathrm{m}$.

al., 2010) and is required for neuronal differentiation. Previous studies in primary cultures show induction of neuronal differentiation by administration of GDNF (Chalazonitis et al., 1998; Hearn et al., 1998; Taraviras et al., 1999; Ngan et al., 2008). In gut explants, GDNF promotes ENS precursor proliferation in the early phase of culture, whereas it promotes neuronal differentiation in later culture periods (Fu et al., 2004), suggesting that GDNF promotes neuronal differentiation at a later postmigratory stage. However, results of in vivo studies are controversial. In the chick embryo, both overexpression and inhibition of Gdnf induces premature neuronal differentiation (Mwizerwa et al., 2011). In mice heterozygous for $G d n f$, which have a reduced rate of neuronal precursor proliferation (Gianino et al., 2003), the rate of neuronal differentiation tends to be higher than that in WT mice (Flynn et al., 2007). Our findings clearly demonstrate that ENS precursors lacking GDNF availability do not differentiate into neurons.

Furthermore, we show that inactivation of GDNF leads to the maintenance of ENS precursors in an undifferentiated state, and that GDNF signal recovery can restart neuronal differentiation of 
ENS precursors lacking GDNF signaling in gut organ culture. Thus, GDNF is required for triggering neuronal differentiation of ENS precursors, and insufficient activation of GDNF signaling appears to be important for the persistence of noncommitted precursors within the MGs until they receive sufficient GDNF signaling for the formation of the SMGs.

Bone morphogenetic proteins (BMPs) also play a role in the long-term developmental processes of the ENS. In vitro neuronal differentiation is enhanced by low concentrations and is reduced by high concentrations of BMP2 or BMP4 (Chalazonitis et al., 2004). In vivo, overexpression of the BMP inhibitor noggin leads to an increase in the number of enteric neurons in both MGs and SMGs, and a decrease in the generation of late-born neurons (Chalazonitis et al., 2008). Combinations of high activation levels of BMP signaling and insufficient activation of GDNF may restrict the extent of neuronal differentiation that occurs during early ENS development.

In Ret-null mice, early migrating ENS precursors undergo massive apoptosis in the foregut at E10.5 (Taraviras et al., 1999; Uesaka et al., 2008). In contrast, at least a portion of ENS precursors in which Ret is inactivated during their migration in the midgut at E10.5 can survive and remain in an immature state. In addition to resistance to the cell death of ENS precursors in the small intestine, postmitotic enteric neurons in the small intestine are also resistant to neuronal death by inactivation of GDNF signaling, in contrast to massive neuronal death in the distal colon (Uesaka et al., 2007, 2008). Since ENS precursors in culture die rapidly without GDNF (Taraviras et al., 1999), other factors, including neurotrophin-3 and serotonergic signaling via the $5-\mathrm{HT}_{4}$ receptor (Chalazonitis et al., 2001; Liu et al., 2009), if any, may support ENS precursor and neuron survival in the small intestine during ENS development. In addition, the close spatial proximity of regions releasing various survival factors appears to augment trophic support promoting ENS cell survival. This situation is different from many other regions of the peripheral nervous system in which a supply of a neurotrophic factor is restricted to the nerve target region. ENS precursors may receive overlapping graded survival signals, which make GDNF signaling a unique requirement for survival in a spatiotemporally restricted pattern.

During development of the MGs, ENS precursors show a lower activation level of ERK by GDNF compared with differentiating neurons. One study reported that activation of the MAPK is necessary for ENS precursor migration. However, their chemotactic response to GDNF is maintained even under conditions of efficient inhibition of the MAPK pathway (Natarajan et al.,
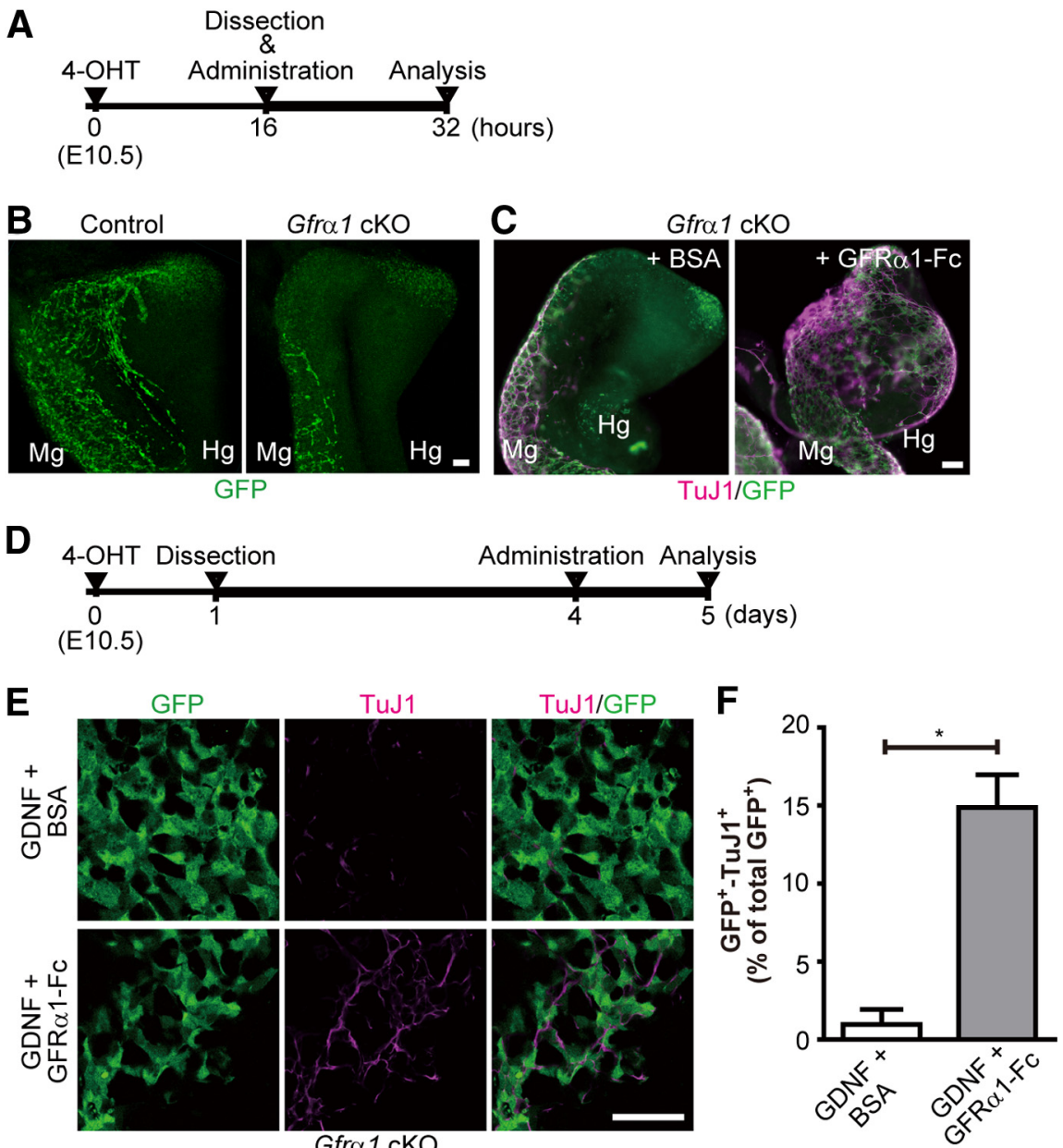

Figure 8. ENS precursors lacking GDNF availability retain migratory and neurogenic potential. $\boldsymbol{A}, 4-0 \mathrm{HT}$ was administered to pregnant females at E10.5. Embryonic guts were dissected out from Gfr $\alpha 1 \mathrm{cKO}$ fetuses $16 \mathrm{~h}$ after injection of 4-0HT and cultured in medium with vehicle (BSA) or soluble GFR $\alpha 1$-Fc for another $16 \mathrm{~h}$. The incubation period of the gut explant is shown as a thick line. $\boldsymbol{B}, \mathrm{GFP}^{+}$cells (green) in the gut of control and Gfr $\alpha 1 \mathrm{cKO}$ fetuses $16 \mathrm{~h}$ after injection of $4-0 \mathrm{HT}$ at E10.5. In the control fetuses, and TuJ1 (magenta) staining of cK0 gut cultured for $16 \mathrm{~h}$ in the presence of vehicle (BSA) or soluble GFR $\alpha 1-\mathrm{Fc}$. In the gut treated $\mathrm{GFP}^{+}$cells (green) were observed with high cell densities, and neurons (magenta) were sparse during the long-term incubation GDNF and BSA had no impact on neuronal differentiation. In contrast, GDNF and soluble GFR $\alpha 1-F c$ administration induced percentage of TuJ1 ${ }^{+}$neurons coexpressing GFP in Gfr $\alpha 1 \mathrm{CKO}$ gut cultured in medium for $3 \mathrm{~d}$, and then treated with GDNF and vehicle (BSA; $n=3$ ) or soluble GFR $\alpha 1-\mathrm{Fc}(n=3)$ for $1 \mathrm{~d} .{ }^{*} p<0.05$, unpaired $t$ test with Welch's correction. Error bars represent SEM. Mg, Midgut; $\mathrm{Hg}$, hindgut. Scale bars, $50 \mu \mathrm{m}$.

2002). Consistent with this, MEK1 inhibitor exhibits little effect on ENS precursor migration in the hindgut (Asai et al., 2006). Another group failed to observe any correlation between ERK activity and migration velocity by ex vivo imaging with FRET biosensors (Goto et al., 2013). Thus, ERK/MAPK cascade may play an important role in neuronal differentiation, and immature ENS precursors may migrate and stay with low levels of ERK activation.

Although our study provides evidence that GDNF signaling levels are highly correlated to the differentiation status of ENS precursors, the exact molecular mechanisms regulating the GDNF signaling levels remain elusive. We speculate that both intracellular and extracellular machineries are involved. As for 
the former, the maintenance of low levels of ERK activation could be due to at least two possibilities: (1) ENS precursors fail to get sufficient access to GDNF; or (2) the GDNF signaling pathway is inhibited by negative regulators that include Sprouty (Spry). Sprouty inhibits GDNF-induced ERK activation in vitro (Ishida et al., 2007), and an in vivo study with Spry2-deficient mice reported that ERK and AKT are hyperactive in response to GDNF in enteric neurons (Taketomi et al., 2005). We therefore examined whether Spry2 deletion leads to activation of ERK in ENS precursors, and, consequently, the depletion of SMG precursors by facilitating differentiation into myenteric neurons. In Spry2null mice, we found ENS precursors with a lower activation level of ERK compared with differentiating neurons, and SMG formation was not impaired (data not shown). These data suggest that a low activation level of ERK is not due to Spry2-mediated inhibition.

The extracellular environment also appears to influence GDNF signaling levels. Differences in the availability of GDNF can occur among ENS precursors, because several previous studies have suggested that GDNF protein seems to be retained close to its site of synthesis. For instance, GDNF overexpression in $M y o-G d n f$ or GFAP-Gdnf transgenic mice has no impact on the serum levels of GDNF (Zhao et al., 2004), and axonal sprouting was elicited locally at the site of GDNF administration in the brain (Rosenblad et al., 1999; Kirik et al., 2000). Spatially restricted action of GDNF upon ENS precursors may be explained by the binding of GDNF to 2-O-sulfate-rich, heparin-related glycosaminoglycan (Rickard et al., 2003), and to GFR $\alpha 1$ expressed by mesenchymal and glial lineage cells in an autocrine fashion. Further studies will be required to fully understand the regulatory mechanism of GDNF signaling in ENS precursors.

In summary, our data indicate that GDNF can drive the migration of ENS precursors expressing Sox10, which is required for maintenance of the undifferentiated precursor state, and inhibits neuronal differentiation of NC stem cells (Kim et al., 2003). In addition, GDNF signaling contributes to the downregulation of Sox10 in ENS precursors and triggers neuronal differentiation, whereas ENS precursors that persist in the MG exhibit minimal activation of GDNF signaling. By exquisite control of GDNF signaling in ENS precursors, the ENS is able to balance MG formation and SMG precursor cell maintenance, ensuring proper development of the SMGs. These findings are highly relevant to human diseases that affect ENS precursors, such as Hirschsprung disease. They also provide novel insights into the molecular mechanisms that regulate ENS precursor cell maintenance and differentiation, and will enhance future attempts to replace missing neurons in the gut.

\section{References}

Airaksinen MS, Saarma M (2002) The GDNF family: signalling, biological functions and therapeutic value. Nat Rev Neurosci 3:383-394. CrossRef Medline

Asai N, Fukuda T, Wu Z, Enomoto A, Pachnis V, Takahashi M, Costantini F (2006) Targeted mutation of serine 697 in the Ret tyrosine kinase causes migration defect of enteric neural crest cells. Development 133:45074516. CrossRef Medline

Baloh RH, Enomoto H, Johnson EM Jr, Milbrandt J (2000) The GDNF family ligands and receptors-implications for neural development. Curr Opin Neurobiol 10:103-110. CrossRef Medline

Cacalano G, Fariñas I, Wang LC, Hagler K, Forgie A, Moore M, Armanini M, Phillips H, Ryan AM, Reichardt LF, Hynes M, Davies A, Rosenthal A (1998) GFR $\alpha 1$ is an essential receptor component for GDNF in the developing nervous system and kidney. Neuron 21:53-62. CrossRef Medline

Chalazonitis A, Rothman TP, Chen J, Gershon MD (1998) Age-dependent differences in the effects of GDNF and NT-3 on the development of neurons and glia from neural crest-derived precursors immunoselected from the fetal rat gut: expression of GFR $\alpha-1$ in vitro and in vivo. Dev Biol 204:385-406. CrossRef Medline

Chalazonitis A, Pham TD, Rothman TP, DiStefano PS, Bothwell M, BlairFlynn J, Tessarollo L, Gershon MD (2001) Neurotrophin-3 is required for the survival-differentiation of subsets of developing enteric neurons. J Neurosci 21:5620-5636. Medline

Chalazonitis A, D'Autréaux F, Guha U, Pham TD, Faure C, Chen JJ, Roman D, Kan L, Rothman TP, Kessler JA, Gershon MD (2004) Bone morphogenetic protein-2 and -4 limit the number of enteric neurons but promote development of a TrkC-expressing neurotrophin-3-dependent subset. J Neurosci 24:4266-4282. CrossRef Medline

Chalazonitis A, Pham TD, Li Z, Roman D, Guha U, Gomes W, Kan L, Kessler JA, Gershon MD (2008) Bone morphogenetic protein regulation of enteric neuronal phenotypic diversity: relationship to timing of cell cycle exit. J Comp Neurol 509:474-492. CrossRef Medline

Durbec PL, Larsson-Blomberg LB, Schuchardt A, Costantini F, Pachnis V (1996) Common origin and developmental dependence on c-ret of subsets of enteric and sympathetic neuroblasts. Development 122:349-358. Medline

Enomoto H, Araki T, Jackman A, Heuckeroth RO, Snider WD, Johnson EM Jr, Milbrandt J (1998) GFR $\alpha 1$-deficient mice have deficits in the enteric nervous system and kidneys. Neuron 21:317-324. CrossRef Medline

Flynn B, Bergner AJ, Turner KN, Young HM, Anderson RB (2007) Effect of Gdnf haploinsufficiency on rate of migration and number of enteric neural crest-derived cells. Dev Dyn 236:134-141. CrossRef Medline

Fu M, Lui VC, Sham MH, Pachnis V, Tam PK (2004) Sonic hedgehog regulates the proliferation, differentiation, and migration of enteric neural crest cells in gut. J Cell Biol 166:673-684. CrossRef Medline

Fukuda T, Kiuchi K, Takahashi M (2002) Novel mechanism of regulation of Rac activity and lamellipodia formation by RET tyrosine kinase. J Biol Chem 277:19114-19121. CrossRef Medline

Gershon MD, Chalazonitis A, Rothman TP (1993) From neural crest to bowel: development of the enteric nervous system. J Neurobiol 24:199214. CrossRef Medline

Gianino S, Grider JR, Cresswell J, Enomoto H, Heuckeroth RO (2003) GDNF availability determines enteric neuron number by controlling precursor proliferation. Development 130:2187-2198. CrossRef Medline

Golden JP, DeMaro JA, Osborne PA, Milbrandt J, Johnson EM Jr (1999) Expression of neurturin, GDNF, and GDNF family-receptor mRNA in the developing and mature mouse. Exp Neurol 158:504-528. CrossRef Medline

Goto A, Sumiyama K, Kamioka Y, Nakasyo E, Ito K, Iwasaki M, Enomoto H, Matsuda M (2013) GDNF and endothelin 3 regulate migration of enteric neural crest-derived cells via protein kinase A and Racl. J Neurosci 33:4901-4912. CrossRef Medline

Gould TW, Yonemura S, Oppenheim RW, Ohmori S, Enomoto H (2008) The neurotrophic effects of glial cell line-derived neurotrophic factor on spinal motoneurons are restricted to fusimotor subtypes. J Neurosci 28: 2131-2146. CrossRef Medline

Hayashi S, McMahon AP (2002) Efficient recombination in diverse tissues by a tamoxifen-inducible form of Cre: a tool for temporally regulated gene activation/inactivation in the mouse. Dev Biol 244:305-318. CrossRef Medline

Hearn CJ, Murphy M, Newgreen D (1998) GDNF and ET-3 differentially modulate the numbers of avian enteric neural crest cells and enteric neurons in vitro. Dev Biol 197:93-105. CrossRef Medline

Heuckeroth RO, Lampe PA, Johnson EM, Milbrandt J (1998) Neurturin and GDNF promote proliferation and survival of enteric neuron and glial progenitors in vitro. Dev Biol 200:116-129. CrossRef Medline

Heuckeroth RO, Enomoto H, Grider JR, Golden JP, Hanke JA, Jackman A, Molliver DC, Bardgett ME, Snider WD, Johnson EM Jr, Milbrandt J (1999) Gene targeting reveals a critical role for neurturin in the development and maintenance of enteric, sensory, and parasympathetic neurons. Neuron 22:253-263. CrossRef Medline

Honma Y, Araki T, Gianino S, Bruce A, Heuckeroth R, Johnson E, Milbrandt J (2002) Artemin is a vascular-derived neurotropic factor for developing sympathetic neurons. Neuron 35:267-282. CrossRef Medline

Ishida M, Ichihara M, Mii S, Jijiwa M, Asai N, Enomoto A, Kato T, Majima A, Ping J, Murakumo Y, Takahashi M (2007) Sprouty2 regulates growth 
and differentiation of human neuroblastoma cells through RET tyrosine kinase. Cancer Sci 98:815-821. CrossRef Medline

Jiang Y, Liu MT, Gershon MD (2003) Netrins and DCC in the guidance of migrating neural crest-derived cells in the developing bowel and pancreas. Dev Biol 258:364-384. CrossRef Medline

Jing S, Wen D, Yu Y, Holst PL, Luo Y, Fang M, Tamir R, Antonio L, Hu Z, Cupples R, Louis JC, Hu S, Altrock BW, Fox GM (1996) GDNF-induced activation of the ret protein tyrosine kinase is mediated by GDNFR- $\alpha$, a novel receptor for GDNF. Cell 85:1113-1124. CrossRef Medline

Kim J, Lo L, Dormand E, Anderson DJ (2003) SOX10 maintains multipotency and inhibits neuronal differentiation of neural crest stem cells. Neuron 38:17-31. CrossRef Medline

Kirik D, Rosenblad C, Björklund A (2000) Preservation of a functional nigrostriatal dopamine pathway by GDNF in the intrastriatal 6-OHDA lesion model depends on the site of administration of the trophic factor. Eur J Neurosci 12:3871-3882. CrossRef Medline

Lewandoski M, Meyers EN, Martin GR (1997) Analysis of Fgf8 gene function in vertebrate development. Cold Spring Harb Symp Quant Biol 62: 159-168. CrossRef Medline

Liu MT, Kuan YH, Wang J, Hen R, Gershon MD (2009) 5-HT4 receptormediated neuroprotection and neurogenesis in the enteric nervous system of adult mice. J Neurosci 29:9683-9699. CrossRef Medline

Luo W, Enomoto H, Rice FL, Milbrandt J, Ginty DD (2009) Molecular identification of rapidly adapting mechanoreceptors and their developmental dependence on ret signaling. Neuron 64:841-856. CrossRef Medline

Moore MW, Klein RD, Fariñas I, Sauer H, Armanini M, Phillips H, Reichardt LF, Ryan AM, Carver-Moore K, Rosenthal A (1996) Renal and neuronal abnormalities in mice lacking GDNF. Nature 382:76-79. CrossRef Medline

Mwizerwa O, Das P, Nagy N, Akbareian SE, Mably JD, Goldstein AM (2011) Gdnf is mitogenic, neurotrophic, and chemoattractive to enteric neural crest cells in the embryonic colon. Dev Dyn 240:1402-1411. CrossRef Medline

Natarajan D, Marcos-Gutierrez C, Pachnis V, de Graaff E (2002) Requirement of signalling by receptor tyrosine kinase RET for the directed migration of enteric nervous system progenitor cells during mammalian embryogenesis. Development 129:5151-5160. Medline

Ngan ES, Shum CK, Poon HC, Sham MH, Garcia-Barcelo MM, Lui VC, Tam PK (2008) Prokineticin-1 (Prok-1) works coordinately with glial cell line-derived neurotrophic factor (GDNF) to mediate proliferation and differentiation of enteric neural crest cells. Biochim Biophys Acta 1783: 467-478. CrossRef Medline

Nishiyama C, Uesaka T, Manabe T, Yonekura Y, Nagasawa T, Newgreen DF, Young HM, Enomoto H (2012) Trans-mesenteric neural crest cells are the principal source of the colonic enteric nervous system. Nat Neurosci 15:1211-1218. CrossRef Medline

Pachnis V, Mankoo B, Costantini F (1993) Expression of the c-ret protooncogene during mouse embryogenesis. Development 119:1005-1017. Medline

Paratcha G, Ledda F, Baars L, Coulpier M, Besset V, Anders J, Scott R, Ibáñez CF (2001) Released GFRalphal potentiates downstream signaling, neuronal survival, and differentiation via a novel mechanism of recruitment of c-Ret to lipid rafts. Neuron 29:171-184. CrossRef Medline

Pham TD, Gershon MD, Rothman TP (1991) Time of origin of neurons in the murine enteric nervous system: sequence in relation to phenotype. J Comp Neurol 314:789-798. CrossRef Medline

Pichel JG, Shen L, Sheng HZ, Granholm AC, Drago J, Grinberg A, Lee EJ, Huang SP, Saarma M, Hoffer BJ, Sariola H, Westphal H (1996) Defects in enteric innervation and kidney development in mice lacking GDNF. Nature 382:73-76. CrossRef Medline

Rickard SM, Mummery RS, Mulloy B, Rider CC (2003) The binding of human glial cell line-derived neurotrophic factor to heparin and heparan sulfate: importance of 2-O-sulfate groups and effect on its interaction with its receptor, GFR $\alpha 1$. Glycobiology 13:419-426. CrossRef Medline

Rosenblad C, Kirik D, Devaux B, Moffat B, Phillips HS, Björklund A (1999)
Protection and regeneration of nigral dopaminergic neurons by neurturin or GDNF in a partial lesion model of Parkinson's disease after administration into the striatum or the lateral ventricle. Eur J Neurosci 11:15541566. CrossRef Medline

Sánchez MP, Silos-Santiago I, Frisen J, He B, Lira SA, Barbacid M (1996) Renal agenesis and the absence of enteric neurons in mice lacking GDNF. Nature 382:70-73. CrossRef Medline

Schuchardt A, D'Agati V, Larsson-Blomberg L, Costantini F, Pachnis V (1994) Defects in the kidney and enteric nervous system of mice lacking the tyrosine kinase receptor Ret. Nature 367:380-383. CrossRef Medline

Shen L, Pichel JG, Mayeli T, Sariola H, Lu B, Westphal H (2002) Gdnf haploinsufficiency causes Hirschsprung-like intestinal obstruction and earlyonset lethality in mice. Am J Hum Genet 70:435-447. CrossRef Medline

Shinohara R, Thumkeo D, Kamijo H, Kaneko N, Sawamoto K, Watanabe K, Takebayashi H, Kiyonari H, Ishizaki T, Furuyashiki T, Narumiya S (2012) A role for mDia, a Rho-regulated actin nucleator, in tangential migration of interneuron precursors. Nat Neurosci 15:373-380:373-380, S1-S2. CrossRef Medline

Stewart AL, Young HM, Popoff M, Anderson RB (2007) Effects of pharmacological inhibition of small GTPases on axon extension and migration of enteric neural crest-derived cells. Dev Biol 307:92-104. CrossRef Medline

Taketomi T, Yoshiga D, Taniguchi K, Kobayashi T, Nonami A, Kato R, Sasaki M, Sasaki A, Ishibashi H, Moriyama M, Nakamura K, Nishimura J, Yoshimura A (2005) Loss of mammalian Sprouty2 leads to enteric neuronal hyperplasia and esophageal achalasia. Nat Neurosci 8:855-857. CrossRef Medline

Taraviras S, Marcos-Gutierrez CV, Durbec P, Jani H, Grigoriou M, Sukumaran M, Wang LC, Hynes M, Raisman G, Pachnis V (1999) Signalling by the RET receptor tyrosine kinase and its role in the development of the mammalian enteric nervous system. Development 126:2785-2797. Medline

Uesaka T, Enomoto H (2010) Neural precursor death is central to the pathogenesis of intestinal aganglionosis in Ret hypomorphic mice. J Neurosci 30:5211-5218. CrossRef Medline

Uesaka T, Jain S, Yonemura S, Uchiyama Y, Milbrandt J, Enomoto H (2007) Conditional ablation of GFR $\alpha 1$ in postmigratory enteric neurons triggers unconventional neuronal death in the colon and causes a Hirschsprung's disease phenotype. Development 134:2171-2181. CrossRef Medline

Uesaka T, Nagashimada M, Yonemura S, Enomoto H (2008) Diminished Ret expression compromises neuronal survival in the colon and causes intestinal aganglionosis in mice. J Clin Invest 118:1890-1898. CrossRef Medline

Wang H, Hughes I, Planer W, Parsadanian A, Grider JR, Vohra BP, KellerPeck C, Heuckeroth RO (2010) The timing and location of glial cell line-derived neurotrophic factor expression determine enteric nervous system structure and function. J Neurosci 30:1523-1538. CrossRef Medline

Young HM, Hearn CJ, Farlie PG, Canty AJ, Thomas PQ, Newgreen DF (2001) GDNF is a chemoattractant for enteric neural cells. Dev Biol 229: 503-516. CrossRef Medline

Young HM, Bergner AJ, Müller T (2003) Acquisition of neuronal and glial markers by neural crest-derived cells in the mouse intestine. J Comp Neurol 456:1-11. CrossRef Medline

Young HM, Bergner AJ, Anderson RB, Enomoto H, Milbrandt J, Newgreen DF, Whitington PM (2004) Dynamics of neural crest-derived cell migration in the embryonic mouse gut. Dev Biol 270:455-473. CrossRef Medline

Yu T, Scully S, Yu Y, Fox GM, Jing S, Zhou R (1998) Expression of GDNF family receptor components during development: implications in the mechanisms of interaction. J Neurosci 18:4684-4696. Medline

Zhao Z, Alam S, Oppenheim RW, Prevette DM, Evenson A, Parsadanian A (2004) Overexpression of glial cell line-derived neurotrophic factor in the CNS rescues motoneurons from programmed cell death and promotes their long-term survival following axotomy. Exp Neurol 190:356372. CrossRef Medline 